\title{
REVISTA BRASILFIRA DE
}

AGRICULTURA IRRIGADA

Revista Brasileira de Agricultura Irrigada v.12, nº.4, p. 2808 - 2813, 2018

ISSN 1982-7679 (On-line)

Fortaleza, CE, INOVAGRI - http://www.inovagri.org.br

DOI: $10.7127 /$ rbai.v12n400991

Protocolo 991.18 - 09/07/2018 Aprovado em 10/07/2018

\section{PRODUÇ̃̃O DE BIOPESTICIDAS PARA O CONTROLE ECOLÓGICO DE PRAGAS AGRÍCOLAS EM HORTAS ORGÂNICAS}

\author{
Waleska Peixoto Xavier ${ }^{1}$, Elísia Gomes Ramos ${ }^{1}$, Glaudjane da Silva Viana ${ }^{1}$, Sebastião \\ Martinho Chiquete $^{1}$, Albanise Barbosa Marinho ${ }^{2}$, Francisca Robevania Medeiros Borges ${ }^{3}$
}

\begin{abstract}
RESUMO
A produção de hortaliças em sistema orgânico demanda tecnologias que respeitem os processos ecológicos. Dentre elas, a produção de insumos destinados a este tipo de cultivo, seja para a produção de mudas, rotação e consorciação de culturas ou até mesmo o manejo de pragas e doenças. O presente trabalho foi conduzido por estudantes do curso de Agronomia, vinculados ao grupo de Pesquisa em Biofertirrigação (GPBio), através de um projeto de extensão da Universidade da Integração Internacional da Lusofonia Afro-Brasileira (UNILAB). Além da instalação de hortas orgânicas comunitárias, este trabalho objetivou a produção de biopesticidas e a realização de oficinas e palestras no Centro de Convivência Antônio Diogo, no município de Redenção - Ceará. Após a realização das oficinas e acompanhamento dos cultivos, pôde-se observar uma maior integração das famílias residentes na Colônia e aprendizados em noções de agricultura orgânica, hábitos alimentares mais saudáveis, manejo de horta orgânica em residências e métodos de controle de pragas agrícolas, com manejo ecológico. A aplicação dos biopesticidas denotou efeito positivo nas hortas orgânicas, sendo recomendado para uso em outras culturas, conforme interesse da comunidade.
\end{abstract}

Palavras-chave: Sustentabilidade, agricultura, educação ambiental.

\section{PRODUCTION OF BIOPESTICIDES FOR THE ECOLOGICAL CONTROL OF AGRICULTURAL PLAGUES IN ORGANIC VEGETABLES}

\begin{abstract}
The production of vegetables in the organic system demands technologies that respect ecological processes. Among them, the production of inputs destined to this type of crop, whether for the production of seedlings, rotation and consortium of crops or even the management of pests and diseases. The present work was conducted by students of the Agronomy course, linked to the Biofertirrigation Research Group (GPBio), through an

\footnotetext{
${ }^{1}$ Graduandos em Agronomia, UNILAB, IDR, emails: waleskajalles23@gmail.com; lisyramos16@hotmail.com; glauagronomia@gmail.com; sebastiaomartinho09@hotmail.com.

${ }^{2}$ Doutora em Produção Vegetal, Prof ${ }^{a}$, UNILAB, IDR, email: albanise@unilab.edu.br.

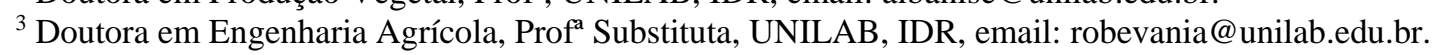


extension project of the University of International Integration of Afro-Brazilian Lusophony (UNILAB). In addition to the installation of community organic gardens, this work aimed at the production of biopesticides and the realization of workshops and lectures in the spaces of coexistence of Antônio Diogo Colony, in the municipality of Redenção - Ceará. After the workshops and crop follow-up, it was possible to observe a greater integration of families living in the Colony and learning in notions of organic agriculture, healthier eating habits, organic gardening in their homes and methods of agricultural pest control, with ecological management. The application of biopesticides had a positive effect on organic gardens, being recommended for use in other crops, according to the interest of the community.

Keywords: Sustainability, agriculture, environmental education.

\section{INTRODUÇÃO}

Na última década, o Brasil alcançou a posição de maior consumidor mundial de pesticidas (RIBAS; MATSUMURA, 2009). Almeida et al. (2009) afirmam que, em hortaliças, o consumo de pesticida aumentou, de 2004 a 2008, em 8\% no Brasil.

Os métodos alternativos de controle, se utilizados corretamente, podem manter a população da praga em níveis satisfatórios, ou seja, em níveis abaixo daqueles que causariam danos econômicos (FERNANDES; CARNEIRO, 2006). Notadamente, as hortaliças estão entre as culturas mais propícias à utilização destes métodos, especialmente, porque são destinadas à alimentação humana, muitas vezes consumidas in natura (PATRÍCIO, 2007).

De acordo com Penteado (2001), são considerados defensivos alternativos e naturais todos os produtos químicos, biológicos, orgânicos ou naturais, que apresentem as seguintes características: praticamente não tóxicos, de baixa ou nenhuma agressividade ao homem e à natureza, eficientes no combate aos insetos e microorganismos nocivos, de custo reduzido, de simplicidade de manejo e aplicação, disponibilidade do produto ou do material para aquisição.

A construção de hortas e a propagação de técnicas ambientais no Centro de Convivência Antônio Diogo surgiram como uma oportunidade de reforçar o convívio social entre os moradores e estimular uma alimentação saudável das famílias residentes.

Fundada em 1928, a Colônia ou Centro de Convivência, tinha como objetivo retirar pessoas acometidas por hanseníase da sociedade, considerando que o isolamento era a única medida profilática aceitável. Atualmente, as famílias residentes no Centro de Convivência são constituídas de pessoas que foram acometidas ou não pela doença da hanseníase.

Além da instalação de hortas orgânicas comunitárias, este trabalho objetivou a produção de biopesticidas e a realização de oficinas e palestras no Centro de Convivência Antônio Diogo, no município de Redenção Ceará, abrangendo temas como inseticidas naturais e controle ecológico de pragas agrícolas.

\section{MATERIAL E MÉTODOS}

O Centro de Convivência Antônio Diogo está localizado no município de Redenção CE e possui cerca de 51 famílias. O projeto de extensão foi desenvolvido por docentes e discentes da Universidade da Integração da Lusofonia Afro-brasileira (UNILAB) em parceria com a equipe gestora do Centro de Convivência. O trabalho foi realizado no período de julho de 2015 até agosto de 2016.

Inicialmente, foram realizadas reuniões com a equipe gestora, que selecionou famílias que possuíam aptidão agrícola e interesse em implantar hortas orgânicas em suas residências. Em seguida, avaliou-se o nível de interesse das famílias na participação do projeto. Todas as famílias aprovaram a proposta.

Para o preparo dos canteiros da horta orgânica em cada propriedade utilizou-se 
adubação orgânica com esterco bovino. A escolha das culturas implantadas foi feita em comum acordo com o interesse das famílias, levando em consideração também a disponibilidade de mudas e sementes, dentre elas alface (Lactuca sativa), tomate (Solanum lycopersicum), cebola (Allium cepa), cebolinha (Allium schoenoprasum), coentro (Coriandrum sativum), berinjela (Solanum melongena), pimentão (Capsicum annuum), couve-manteiga (Brassica oleracea) e pepino (Cucumis sativus).

Periodicamente, foram realizadas visitas para suporte técnico na condução das hortas orgânicas. Em paralelo, foram ofertadas as oficinas de noções de agricultura orgânica, hábitos alimentares mais saudáveis, manejo de horta orgânica, irrigação nas hortas, produção de inseticidas naturais e controle de pragas agrícolas, com manejo ecológico.

$\mathrm{Na}$ primeira etapa das oficinas, realizouse uma apresentação teórica, apresentando os conceitos de agricultura orgânica, os malefícios do uso de agrotóxicos na produção de plantas, principalmente das hortaliças, o manejo da horta e algumas pragas e doenças comuns que poderiam ocorrer na horta orgânica, causando-lhe danos econômicos ou à saúde.

Na segunda etapa, houve a produção e a aplicação dos biopesticidas nas hortas orgânicas, com a participação ativa dos agricultores familiares. Preparou-se o inseticida macerado de alho e cebola (COMISSÃO PASTORAL DA TERRA, 2016) para prevenção e combate de lagartas, pulgões e cochonilhas; inseticida à base de castanha de caju e álcool; e o repelente natural de citronela, para afastar moscas, mosquitos e insetos em geral. As aplicações dos biopesticidas ocorreram quinzenalmente ou conforme a necessidade ao constatar infestação de alguma praga agrícola.

Para o preparo do macerado de alho e cebola, utilizou-se cinco dentes de alho e uma cebola branca para cada litro de água, misturando-se os ingredientes e colocando-se em um pulverizador. Seguindo a recomendação de Comissão Pastoral da Terra (2016), a aplicação nas plantas ocorreu logo após o preparo.

Para o preparo do biopesticida à base de castanha de caju utilizou-se as castanhas cruas, cortadas em pedaços. Após o corte, estas foram colocadas em uma garrafa de $500 \mathrm{~mL}$ e misturados com álcool, na mesma proporção. Essa solução ficou em infusão por um período de três dias. Para aplicação dessa solução foi orientado para os agricultores que utilizassem 2,5 mL para cada 1 litro de água. Esse biopesticida foi utilizado no controle de lagartas, formigas e gafanhotos, mas também é eficiente no controle de cochonilhas.

No preparo do biopesticida à base de citronela (Cymbopogon nardus), as folhas de citronela foram colocadas em uma garrafa de $500 \mathrm{~mL}$ e o volume completado com álcool. Essa solução ficou em repouso por treze dias em local seco e sem iluminação. Após esse período, aplicou-se sobre as plantas para controle de pulgões e formigas.

\section{RESULTADOS E DISCUSSÕES}

As culturas implantadas nas hortas apresentaram um bom desenvolvimento. Durante o período de realização do projeto, foi possível cultivar mais de um ciclo das variedades escolhidas, sendo plantadas por mudas ou sementes.

No cultivo das hortas utilizou-se manejo orgânico, sem adição de insumos químicos, o que garante a preservação dos recursos naturais e o equilíbrio ambiental, especialmente do solo. Oliveira et al. (2008) afirmam que a introdução de contaminantes no solo, das mais variadas fontes, causa inúmeras consequências negativas para a cadeia alimentar, para a saúde pública e para os diversos ecossistemas e recursos naturais.

Com o uso de tecnologias agroecológicas nas hortas, houve uma produção de frutos mais saudáveis, livre de doenças e pragas, proporcionando mudança de hábitos alimentares nas famílias, tornando-os mais saudáveis. Estimativas da Organização Mundial da Saúde (OMS) apontam que cerca de 2,7 milhões das mortes mundiais registradas em 2000 poderiam ter sido evitadas com o 
consumo adequado de frutas, legumes e verduras, o que reduziria em $1,8 \%$ a carga global de doenças (LOCK et al., 2005).

A colheita das hortas foi produtiva, assim como o manejo utilizado durante todo o projeto. As visitas periodicamente realizadas às famílias proporcionaram aos agricultores um suporte técnico agrícola favorável, como observações de campo em relação aos ataques de pragas, surgimento de doenças, deficiência nutricional ou déficit hídrico, de suma importância para o aprendizado de ambas as partes.

Durante o desenvolvimento das culturas agrícolas, as hortas apresentaram um alto nível de ataque de pragas, como cochonilhas, pulgões, formigas, gafanhotos e lagartas, principalmente durante o período chuvoso. Para solucionar os problemas encontrados, foram elaborados e apresentados aos agricultores os biopesticidas à base de alho e cebola, castanha de caju e citronela.

O uso de derivados botânicos, substâncias com menores riscos à saúde humana e ao ambiente, vêm sendo avaliados como pesticidas naturais. No caso dos insetos, os biopesticidas podem causar efeitos como repelência, inibição de oviposição e da alimentação e alterações no sistema hormonal (RODRIGUES et al., 2014).

Os bioinseticidas de castanha de caju e o macerado de alho e cebola aplicados como medida de controle em lagartas, formigas e gafanhotos reduziu a população dessas pragas, diminuindo as danificações causadas por elas nas culturas agrícolas. Face ao exposto, foi possível denotar efeito positivo durante as aplicações e foi reconhecida pelos agricultores a eficiência desses produtos em suas hortas.

O líquido da castanha de caju (LCC), contido no mesocarpo alveolado do fruto (castanha), possui propriedades cáusticas e inflamáveis e é comercializado por indústrias, para resinas e freios, e medicinal para antissépticos e vermífugos (MAZZETTO; LOMONACO, 2009), porém tem mostrado potencial inseticida (PORTO et al., 2013).

Estudos desenvolvidos por Vieira et al. (2006) demonstram que o LCC se mostrou tóxico para algumas pragas agrícolas quando aplicado topicamente, apresentando boa atividade por contato. Porto et al. (2013) avaliando o potencial inseticida do LCC sobre larvas de A. aegypti, comprovaram a eficácia do insumo e indicaram que, mesmo na entressafra da produção de caju, o LCC pode ser refrigerado para utilização sem perder a eficiência.

Convém mencionar que a matéria prima empregada nos biopesticidas é derivada de plantas, o que reduz a possibilidade de impacto ambiental sobre o ecossistema pela exploração destas espécies vegetais. Sousa et al. (2014) cita que em termos de pequenas propriedades rurais, as plantas que podem ser utilizadas como inseticidas devem ser plantadas no próprio local, com o objetivo de facilitar a coleta dos materiais vegetais e sua manipulação.

Além disso, o potencial dos inseticidas a base de princípios ativos vegetais proporciona a utilização de moléculas que, pela complexidade de composição, diminuem os riscos do aparecimento de resistência (GALLO et al. 2002), muitas vezes causada pela aplicação em larga escala de inseticidas e sem controle rigoroso.

Os agricultores das hortas orgânicas relataram que houve uma redução na quantidade de moscas e mosquitos no local da horta, facilitando o manejo durante os tratos culturais, após a aplicação do biopesticida à base de citronela.

O óleo extraído das folhas da citronela tem aproximadamente $40 \%$ de aldeído citronelal, e pequenas proporções de geraniol, citronelol e ésteres. O citronelol é um excelente aromatizante de ambientes, repelentes de insetos, e tem apresentado ação anti-microbiana local e acaricida (MARCO et al., 2007).

Veloso et al. (2015) avaliando o efeito larvicida do óleo essencial do manjericão (Ocimum basilicum L.) e do capim citronela (Cymbopogon nardus L.) verificaram que as alíquotas de 5,0, 7,5 e 10,0 $\mu \mathrm{L}$ do óleo de capim citronela promoveram maior ação larvicida, apresentando a partir de seis horas de avaliação 100\% de larvas mortas.

A utilização de biopesticidas como uma 
estratégia de controle de pragas, principalmente insetos, é promissora, todavia, devem ser ampliadas as pesquisas com o uso de extratos e óleos essenciais, ensaios em condições de campo e estudos de controle de qualidade para viabilizar uma maior adoção desses produtos naturais (SOUSA et al., 2014).

\section{CONCLUSÕES}

A oficina sobre os inseticidas naturais despertou na comunidade e nos agricultores familiares o interesse pelo cultivo de hortaliças e plantas medicinais, com controle ecológico de pragas e doenças, além de ressaltar a importância da agricultura orgânica.

Os biopesticidas apresentados neste estudo podem ser uma opção viável ao uso de agrotóxicos, porém, há necessidade de mais estudos, principalmente relacionando o tipo de controle com as pragas e doenças particulares.

A relação entre o número de aplicações com a incidência de pragas e doenças, não foi avaliada neste estudo. Contudo, foi observado que nas hortas em que os biopesticidas eram utilizados com mais frequência houve menores perdas da produção por ataques de pragas.

\section{AGRADECIMENTOS}

Ao grupo de pesquisa GPBIO (Grupo de Pesquisa em Biofertirrigação) pelo apoio nas atividades desenvolvidas durante o projeto.

\section{REFERÊNCIAS}

ALMEIDA, V. E. S.; CARNEIRO, F. F.; VILELA, N. J. Agrotóxicos em hortaliças: segurança alimentar, riscos socioambientais e políticas públicas para promoção da saúde. Actas em Saúde Coletiva, v. 4, n. 4, p. 84-99, 2009.

COMISSÃO PASTORAL DA TERRA. Práticas agroecológicas: saberes e fazeres da agricultura camponesa. Goiânia: Editora Cirgráfica, 2016. 94 p.

FERNANDES, O. A.; CARNEIRO, T. R. Controle biológico de Spodoptera frugiperda no Brasil. In: PINTO, A. S.; NAVA, D. E.; ROSSI, M. M.; MALERBO-SOUZA, D. T. (Eds.). Controle Biológico na Prática. ESALQ/USP, Piracicaba: CP 2, 2006. p. 7582.

GALLO, D.; NAKANO, O., SILVEIRA NETO, S., CARVALHO, R. P. L., BAPTISTA, G. C., BERTI FILHO, E., PARRA, J. R. P., ZUCCHI, R. A., ALVES, S. B., VENDRAMIM, J. D., MARCHINI, L. C., LOPES, J. R. S.; OMOTO, C. Entomologia Agrícola. Piracicaba: FEALQ, 2002. 920 p.

LOCK, K.; POMERLEAU, J.; ALTMANN, D. R.; MCKEE, M. The global burden of disease attributable to low consumption of fruit and vegetables: implications for the global strategy on diet. Bull World Health Organ, v. 83, n. 2, p. 100108, $2005 . \quad$ DOI:10.1590/S004296862005000200010 .

MARCO, C. A.; INNECCO, R.; MATTOS, S. H.; BORGES, N. S. S.; NAGÃO, E. V. Características do óleo essencial de capimcitronela em função de espaçamento, altura e época corte. Horticultura Brasileira, v.25, n.3, p. 429-432, 2007. http://dx.doi.org/10.1590/S0102-

05362007000300020

MAZZETTO, S. E.; LOMONACO, D. O óleo da castanha de caju: oportunidades e desafios no contexto do desenvolvimento e sustentabilidade industrial. Química Nova, v. 32, n.3, p. 732-741, 2009.

OLIVEIRA, S. D.; LEMOS, J. L. S.; BARROS, C. A.; LEITE, S. G. F. Emprego de Fungos Filamentosos na Biorremediação de Solos Contaminados por Petróleo: Estado da Arte. Rio de Janeiro: CETEM/MCT, 2008. 67 p. (Série tecnologia ambiental). 
PATRÍCIO, F. R. A Palestra: Controle de doenças de hortaliças - convencional vs. Alternativo. Biológico, v. 69, p. 87-90, 2007.

PENTEADO, S. R. Agricultura orgânica. Piracicaba: ESALQ. 2001. 41p. (Série Produtor Rural, Edição Especial).

PORTO, K. R. A.; ROEL, A. R.; MACHADO, A. A.; CARDOSO, C. A. L.; SEVERINO, E.; OLIVEIRA, J. M. Atividade inseticida do líquido da castanha de caju sobre larvas de Aedes aegypti (Linnaeus, 1762) (Diptera: Culicidae). Revista Brasileira de Biociências, v. 11, n. 4, p. 419-422, 2013.

RODRIGUES, V. M.; VALENTE, E. C. N.; LIMA, H. M. A.; TRINDADE, R. C. P.; DUARTE, A. G. Avaliação de extratos de Annona muricata L. sobre Aphis craccivora Koch, 1854 (Hemiptera: Aphididae). Revista Brasileira de Agroecologia, v. 9, n. 3, p. 7583, 2014.

RIBAS, P. P.; MATSUMURA, A. T. S. A química dos agrotóxicos: impacto sobre a saúde e meio ambiente. Revista Liberato, v. 10, n. 14, p. 149-158, 2009.

SOUSA, T. P.; SOUSA NETO, E. P.; SILVEIRA, L. R. S.; SANTOS FILHO, E. F.; MARACAJÁ, P. B. Utilização de plantas como repelentes e inseticidas naturais: alternativa de produção orgânica e sustentável na agricultura familiar. Revista Verde de Agroecologia e Desenvolvimento sustentável, v. 9, n.4, p. 57, 2014.

VELOSO, R. A.; CASTRO, H. G.; CARDOSO, D. P.; CHAGAS, L. F. B.; CHAGAS JÚNIOR, A. F. Óleos essenciais de manjericão e capim citronela no controle de larvas de Aedes aegypti. Revista Verde, v. 10, n.2, p 101 - 105, 2015.

VIEIRA, L.; DE BORTOLI, S. A. Efeito do óleo da castanha de caju incorporado na dieta artificial de Anticarsia Gemmatalis Hubner, 1818 (Lepidoptera: Noctuidae). Biológico, v. 68, p. 844-847, 2006. 